\title{
Cytomorphological diagnosis of lymphadenopathy by fine needle aspiration cytology in HIV positive patients and its correlation with CD4 count- a hospital based 2 years cross sectional study
}

\author{
Ratan $\mathrm{K}^{1}$, Bhubon Singh $\mathrm{N}^{2}$, Arun Kumar $\mathrm{K}^{3}$, Shikha $\mathrm{Ng}^{4}$, Niteshor $\mathrm{MS}^{5}$ \\ 1,2,3,4 (Department of Pathology, Regional Institute of Medical Sciences, India) \\ ${ }^{5}$ (Department of Otorhinolaryngology, Regional Institute of Medical Sciences, India)
}

\begin{abstract}
:
Background and objective: To evaluate the role of fine needle aspiration cytology in diagnosis of lymphadenopathy in HIV infected patients and to find out the correlation between cytological findings and CD4 count.

Material and methods: It is a hospital based cross sectional study for 2 years (January 1999 to December 2011). Patients having lymphadenopathy with HIV infections were included in the study. FNAC of the lymph node(s) were done and from the aspirates, the smears were made and air dried and fixed in 95\% ethyl alcohol. Slides were stained routinely with $M G G$ and $A F B$ or other special stains. CD4+ $T$ cell was counted using Fluorescent activated cell sorters. Descriptive statistics and significance testing were carried out by using ANOVA and Post hoc test.

Results: The mean age of presentation was 31.38 years. NSRL (42.1\%) was the most common lesion followed by tubercular lymphadenitis (38.84\%). Granulomatous lymphadenitis $(9.92 \%)$, acute suppurative lymphadenitis (6.61\%) and one case (0.83\%) each of NHL, metastatic lymph node and fungal (P. marneffei) lymphadenitis were the other cytological diagnoses. Maximum number of cases was associated with CD4 count range 101-200 $(43.8 \%)$.

Conclusion FNAC is reliable, safe, cost effective procedure for diagnosis of lymphadenopathy in the entire spectrum of HIV infection.
\end{abstract}

Keywords: FNAC, HIV, Lymphadenopathy, NSRL, Tuberculosis

\section{I. introduction}

Globally, 34.0 million [31.4 million-35.9 million] people were living with HIV at the end of 2011. An estimated $0.8 \%$ of adults aged $15-49$ years worldwide are living with HIV, although the burden of the epidemic continues to vary considerably between countries and regions.(1) India is estimated to have the third highest number of estimated people living with HIV/AIDS, after South Africa and Nigeria (UNAIDS Report on the Global AIDS epidemic 2010). According to the HIV Estimations 2012, the estimated number of people living with HIV/AIDS in India was 20.89 lakh with the adult (15-49 age-group) HIV prevalence at national level 0.27\% in 2011.(2) The first AIDS case in India was detected in 1986 and since then, HIV infection has been reported in all States and Union Territories.

Human immunodeficiency virus infection/Acquired immunodeficiency syndrome (HIV/AIDS) is a disease of the human immune system caused by the human immunodeficiency virus (HIV)(3), belongs to the Lentivirus genus of the Retroviridae family (4) and characterized by profound immune suppression that leads to opportunistic infections, secondary neoplasm, and neurologic manifestations (5). HIV is transmitted primarily through blood and genital fluids and to newborn infants from infected mothers. HIV infects cells by using the CD4 molecule as receptor and chemokine receptors CCR5, CXCR4 as coreceptor. CD+ T cells play pivotal role in regulating both cellular and humoral immune response. CD4+ $\mathrm{T}$ cells orchestrate immune responses by differentiating into $\mathrm{T}$ helper (Th) cell subsets which recruit and activate other immune cells including B cells, CD8+ T cells, macrophages and other effector cells. During primary infection, a high frequency of CD4+ T cells is infected by HIV-1, and lysis or immunologic clearance of these infected cells accounts for the substantial early depletion of CD4+ T cells, particularly when mucosal tissues are sampled ( direct cytopathic effect of HIV-1 ) and Apoptosis of uninfected CD4+T cells was suggested as a mechanism, particularly during the chronic stage of infection and during progression to AIDS.(6) Loss of CD4+ T cells after HIV infection is also a result of several mechanisms such as impairment of de novo production of $\mathrm{T}$ lymphocytes by the thymus, induction of syncytium formation, alteration of membrane permeability, mitochondrial dysfunction, killing by HIV-specific cytotoxic T cells or through expression of DRs due to heightened levels of immune activation. The current CDC classification system for HIV-infected adolescents and adults categorizes persons on the basis of clinical conditions associated with HIV infection and CD4+ T lymphocyte counts(7). 
HIV positive patients and those with AIDS often present with lymphadenopathy. The previous classification of HIV-induced lymphadenopathy in four patterns as follicular hyperplasia, follicular fragmentation, follicular atrophy and follicular depletion, is based on criteria typical of the conventional histology and cytology and is becoming perhaps inadequate to describe the dynamics of lymph node involution that consists of three evolutionary stages: during the first phase, an early deposition of collagen type I predominates; then the breakup of lymph node architecture is evidenced by a decline of the follicular DC network; in the final phase the infiltration of cytotoxic CD8+ lymphocytes (a progressive event starting from the primary infection) becomes massive.(8) The most common conditions affecting the lymph nodes in HIV positive patients are: reactive changes, including progressive generalized lymphadenopathy (PGL); opportunistic infections with Mycobacterium tuberculosis, Mycobacterium avium intracellulare, Histoplasma capsulatum and Cryptococcus neoformans; and malignant conditions such as non-Hodgkin's and Hodgkin's lymphomas and Kaposi's sarcoma(9). Apart from the other causes of lymphadenopathy, HIV infection itself may produce persistent generalized lymphadenopathy (PGL).(10) Fine needle aspiration cytology is a simple, inexpensive, rapid investigative procedure, which can reduce surgical excisions and provide definite guidelines about further management (11). Most opportunistic infections (bacterial and fungal) can be correctly identified and high grade lymphoma can be diagnosed and phenotyped. The purpose of the present study was to evaluate the role of fine needle aspiration cytology in diagnosis of lymphadenopathy in HIV infected patients and to find out the correlation between cytological findings and CD4 count.

\section{Material And Methods}

The study was carried out in the Department of Pathology in collaboration with the Department of Microbiology, Regional Institutes of Medical Sciences (RIMS), Imphal, Manipur, India for a period of two year starting from January 1999 to December 2011. All the patients having lymphadenopathy attending cytology section with HIV infections (diagnosed according to National Aids Control Organisation guidelines) were included in the study. A case of HIV infection refers to the patients who are designated Retro-positive from one of the reference centers for HIV testing approved by NACO after Voluntary Confidential Counseling and Testing Centre (VCCTC). HIV-infected patients on Highly active anti retroviral treatment (HAART) or anti tubercular therapy (ATT) were excluded from the study. FNAC of the lymph node(s) of one site or sites were done with the help of $22 \mathrm{G}$ disposable needle and Cameco syringe holder taking. From the aspirates, the smears were made and air dried and fixed in $95 \%$ ethyl alcohol. Slides were stained routinely with MGG and H \& E, PAP, AFB, PAS or any other special stains were done whenever required. Ziehl-Neelsen stain for acid fast bacilli were done for all the cases with caseation, granuloma and suppuration. For AFB positive cases, report was given as per guidelines of CDC, USA, 1985. For the fungal culture, aspirates were inoculated on two sets of: a) Sabouraud's dextrose agar media (SDA), b) Brain Heart Infusion agar (BHIA). One set was incubated at $37^{\circ} \mathrm{C}$ and another at room temperature. The two tubes was examined everyday for first one week and then on alternate days for next 3 weeks. For the CD4+ T cell count, Fluorescent activated cell sorters (FACS) counter were used for T-lymphocyte subset. Recruitment into the study was done after the approval from the Institutional Ethical Committee. Written informed consent was taken from every case. Descriptive statistics and significance testing were carried out by using ANOVA (Analysis of Variation) and Post hoc test.

\section{Results}

A total of $121 \mathrm{HIV}$ infected patients presenting with lymphadenopathy underwent FNAC. The mean age of presentation was 31.38 years with age range from 5 years to 48 years. The youngest age of the patient was a 5 years old male and the oldest was a 48 years old female. The age distribution of the patient showed that the maximum number of patients belong to the 25 - 34 years age group ( $42.15 \%$ ), followed by $35-44$ years (36 $.36 \%)$. (Table 1 ) In the present study 66 cases $(54.5 \%)$ were males and $55(45.5 \%)$ cases females with male to female ratio of 1.2:1. Most commonly involved site was cervical region $(91 / 121 ; 75 \%)$. Other sites in the order of frequency were the supraclavicular $(6.6 \%)$, axillary and inguinal $(5.7 \%$ each), submental and submandibular regions.

In our present study, non specific reactive lymphadenitis (NSRL) $(51 / 121 ; 42.1 \%)$ was the most common lesion followed by tubercular lymphadenitis (TBLN) (47/121;38.84\%).(Figure1) Non-specific granulomatous lymphadenitis (12;9.92\%) without a known etiolgy, acute suppurative lymphadenitis $(8 ; 6.61 \%)$ with AFB stain negative, and one case $(1 ; 0.83 \%)$ each of Non Hodgkin Lymphoma, metastatic lymph node and fungal (P. marneffei) lymphadenitis were the other cytological diagnoses. (Figure 2)(Figure 3) Most cases TBLN cases were associated with caseation necrosis with well-formed and ill-formed granulomas and few cases were associated with suppuration. Ziehl-Neelsen stain for acid fast bacilli were found to be positive in the most cases of tubercular cases.

Maximum number of cases were associated with CD4 count ranges 101-200 (53/121;43.8\%) and 201$300(24 / 121 ; 19.8 \%)$. CD4 count in NSRL ranged from 101 to more than 501 with the maximum number of 
cases seen in CD4 count $401-500$ cells / cumm (13/51;25.49\%) (mean value $\pm \mathrm{SD} ; 328.04 \pm 123.17$ ). In cases of tubercular lymphadenitis (TBLN), the maximum number $(33 / 47 ; 70.21 \%)$ belonged to the CD4 count between $101-200$ cells/ cu mm. In cases of granulomatous lymphadenitis, CD4 count range was $101-300$ cells/ cu mm with 5/12(41.66\%) each i.e between 101-200 and $201-300$ cells/cu mm. 2 cases (16.66\%) were CD4 count less than 100 cells/cu mm. Metastatic lymph node and P. marneffei lymphadenitis cases had CD4 count below 100 cells/cu mm. NHL case had CD4 count between 101-200 cells/cu mm.(Table 2). Statistical analysis by ANOVA and Post -hoc test (Bonferroni) revealed significant difference between NSRL and TBLN with regard to CD4 Count $(\mathrm{p}<0.001)$. (Table 3)

\section{Discussion}

In our study, the mean age of presentation was 31.38 years with age range from 5 years to 48 years with maximum of cases seen in the age groups 25 - 34 years (42.15\%), and 35 - 44 years (36.36\%). Similar finding were reported by Pairkh U.R. (3), Pandit A.A. et al (12), Saikia U.N. et al (13) and Jayaram G. et al (14) but they reported wider age range. In the present study 66 cases $(54.5 \%)$ were males and $55(45.5 \%)$ cases females with male to female ratio of 1.2:1. On the contrary, Pairkh U.R. et al (3), Bates E.M. et al (9) and Saikia U.N. et al (13) reported much higher male predominance. These differences in age and sex distributions may be due to differences in the incidence, prevalence and mode of transmissions in different geographic locations. Most commonly involved site was cervical region (91/121;75\%). This finding is comparable with Pairkh U.R. et al (3) and Bates E.M. et al (9).

Non specific reactive lymphadenitis (NSRL) $(42.1 \%)$ was the most common lesion followed by tubercular lymphadenitis (38.84\%) in our study. This finding is comparable with Bates E.M. (9), Saikia U.N. et al (13), Reid A.J. et al (15), Bottles K. et al (16), Dominquez A. et al (17). But Pairkh U.R. (3)(40.54\%) and Nayak S. et al (11)(46.8\%) reported tubercular abscess/lymphadenitis as most common lesion in their study. In our study, $12(9.92 \%)$ were found to be granulomatous lymphadenitis. However, Deshmukh A.T. et al (18) reported a higher number of granulomatous lymphadenitis (18.1\%). Eight $(6.61 \%)$ were found to be acute suppurative lymphadenitis. This finding are comparable Bates E.M. (9) and Reid A.J. et al (15). But Pairkh U.R. (3), however, reported higher number of acute suppurative lesion (27.03\%). In the present study, we had a lower rate of lymphoma $(0.83 \%)$ as one case of NHL. Bates E.M. et al (9) and Vanisri et al (19) also reported lower rate of lymphoma as $4 \%$ and $2.7 \%$ respectively. In their study, Reid A.J. et al (15) and Bottles K. et al (16) reported higher rate of lymphoma as $9 \%$ and $20 \%$ respectively. We encountered a case of metastatic lymph node (left cervical) in a case of 45 years old male who also had TBLN (right cervical). One case $(0.83 \%)$ was found to be fungal (P. marneffei) lymphadenitis. Kumarguru et al(20) also reported one case $(0.43 \%)$ of fungal (cryptococcal) lymphadenitis. Bates E.M. et al (9) reported Kaposi sarcoma 15\% and Reid A.J. at el(15) 2\% in their studies. We did not encountered any case of Kaposi sarcoma. Comparison of our findings with other studies is shown in Table 4.

$\mathrm{T}$ he reactive lymphadenitis cases showed highest mean CD4 counts (mean value $\pm \mathrm{SD} ; 328.04 \pm$ 123.17) and in tubercular lymphadenitis (TBLN), $<100-400$ with mean 164.78 cells/ cu mm. Shobhana A. et al (10) also reported highest CD counts with reactive hyperplasia where CD4 count varied between 411 - 945 cells $/ \mu \mathrm{L}$ ), (medium value was $670 \mathrm{cells} / \mu \mathrm{L}$ ) and tuberculous lymphadenitis with their CD4 count varying between 113-422 cells / $\mu \mathrm{L}$ (median value 212 cells $/ \mu \mathrm{L}$ ). Deshmukh A.T. et al (18) also reported highest mean CD4 counts associated with reactive lymphadenitis. Bulakh P.M. et al (21) also found tubercular lymphadenitis with CD4 count more than 100 in $63.3 \%$. NHL case had CD4 count between 101-200 cells/cu mm. This finding is comparable with Shobhana A. et al (10) finding in their study in which NHL was diagnosed in 2 cases (3.7\%) with CD4 count 79 and 113 cells/ $\mu \mathrm{L}$. P. marneffei lymphadenitis cases had CD4 count below 100 cells/cu mm. This finding is comparable with Larsson M. et al (22) in which they found 127 patients with P. marneffei infection were identified and all were HIV-infected with median CD4+ T-cell count was 24 cells $/ \mu$ l. 
V. Figures and Tables

Table 1. Age and sex distribution of HIV patient with Lymphadenopathy

\begin{tabular}{|c|c|c|c|}
\hline $\begin{array}{l}\text { Age group } \\
\text { ( years) } \\
5-14\end{array}$ & $\begin{array}{l}\text { Male } \\
(\%) \\
2(3.03)\end{array}$ & $\begin{array}{l}\text { Female } \\
(\%) \\
0(0.00)\end{array}$ & $\begin{array}{l}\text { Total } \\
(\%) \\
2(1.65)\end{array}$ \\
\hline $15-24$ & $10(15.15)$ & $9(16.36)$ & $19(15.70)$ \\
\hline $25-34$ & $26(39.39)$ & $25(45.45)$ & $51(42.15)$ \\
\hline $35-44$ & $25(37.88)$ & $19(34.55)$ & $44(36.36)$ \\
\hline $45+$ & $3(4.55)$ & $2(3.64)$ & $5(4.13)$ \\
\hline Total & $66(100.00)$ & $55(100.00)$ & $121(100.00)$ \\
\hline
\end{tabular}

\begin{tabular}{|c|c|c|c|c|c|c|c|}
\hline \multicolumn{8}{|c|}{ Range of CD4 Count ( cells $/ \mathrm{mm}^{3}$ ) } \\
\hline Cytodiagnosis & $<100$ & $101-200$ & $201-300$ & $301-400$ & $401-500$ & $<600$ & Total \\
\hline NSRL ${ }^{*}$ & 0 & 12 & 10 & 12 & 13 & 4 & 51 \\
\hline TBLN** & 7 & 33 & 5 & 2 & 0 & 0 & 47 \\
\hline NSGL $^{* * *}$ & 2 & 5 & 5 & 0 & 0 & 0 & 12 \\
\hline $\mathbf{A S L}^{\#}$ & 0 & 2 & 4 & 0 & 1 & 0 & 7 \\
\hline Metastatic LN"\# & 1 & 0 & 0 & 0 & 0 & 0 & 1 \\
\hline NHL ${ }^{q}$ & 0 & 1 & 0 & 0 & 0 & 0 & 1 \\
\hline $\begin{array}{l}\text { Penicillium } \\
\text { marneffei }\end{array}$ & 1 & 0 & 0 & 0 & 0 & 0 & 1 \\
\hline Total & 12 & 53 & 24 & 14 & 14 & 4 & 121 \\
\hline
\end{tabular}

\begin{tabular}{|c|c|c|c|}
\hline Diagnosis & $\begin{array}{l}\text { Mean CD4 cells } \pm \\
\text { SD }\end{array}$ & Signif & \\
\hline Non specific reactive Lymphadenitis & $328.04 \pm 123.17$ & \multirow{5}{*}{$\begin{array}{l}\mathrm{F} \\
15.04\end{array}$} & \multirow{5}{*}{$\begin{array}{c}\mathrm{p} \\
<0.001\end{array}$} \\
\hline Tubercular lymphadenitis & $164.78 \pm 117.20$ & & \\
\hline $\begin{array}{l}\text { Non } \quad \text { Specific } \\
\text { lymphadenitis }\end{array}$ & $155.86 \pm 58.67$ & & \\
\hline Acute Suppurative lymphadenitis & $189.71 \pm 50.71$ & & \\
\hline other & 179. & & \\
\hline
\end{tabular}

\begin{tabular}{|l|l|l|l|l|l|l|}
\hline \multicolumn{6}{|l|}{ Table 4. Comparison of Results of FNAC Findings in HIV Patients with Lymphadenopathy in different studies } \\
\hline $\begin{array}{l}\text { Cytology } \\
\text { Diagnosis }\end{array}$ & $\begin{array}{l}\text { Bates EM et al } \\
(9), 1993 ; \mathrm{n}=27\end{array}$ & $\begin{array}{l}\text { Reid AJ et al } \\
(15) 1998 ; \mathrm{n}=65\end{array}$ & $\begin{array}{l}\text { Bottles K et al } \\
(16), 1988 ; \mathrm{n}=1 \\
21\end{array}$ & $\begin{array}{l}\text { Deshmukh AT } \\
\text { et } \\
(18), 2013 ; \mathrm{n}=4 \\
\text { al }\end{array}$ & $\begin{array}{l}\text { Vanisri HR et } \\
\text { al (19),2013; } \\
\mathrm{n}=36\end{array}$ & $\begin{array}{l}\text { Present study } \\
\mathrm{n}=121\end{array}$ \\
\hline NSRL $^{*}$ & $41 \%$ & $51 \%$ & $50 \%$ & $29.5 \%$ & $36.1 \%$ & $42.1 \%$ \\
\hline TBLN $^{* *}$ & $22 \%$ & $15 \%$ & $17 \%$ & $58.3 \%$ & $58.3 \%$ & $38.9 \%$ \\
\hline Lymphoma & $4 \%$ & $9 \%$ & $20 \%$ & $2.7 \%$ & $2.7 \%$ & $0.8 \%$ \\
\hline $\begin{array}{l}\text { Kaposi } \\
\text { sarcoma }\end{array}$ & $15 \%$ & $2 \%$ & 00 & 00 & 00 \\
\hline Others & $18 \%$ & $3 \%$ & $24.9 \%$ & $2.7 \%$ & $18.2 \%$ \\
\hline * Non specific reactive lymphadenitis; ** Tubercular lymphadenitis \\
\hline
\end{tabular}




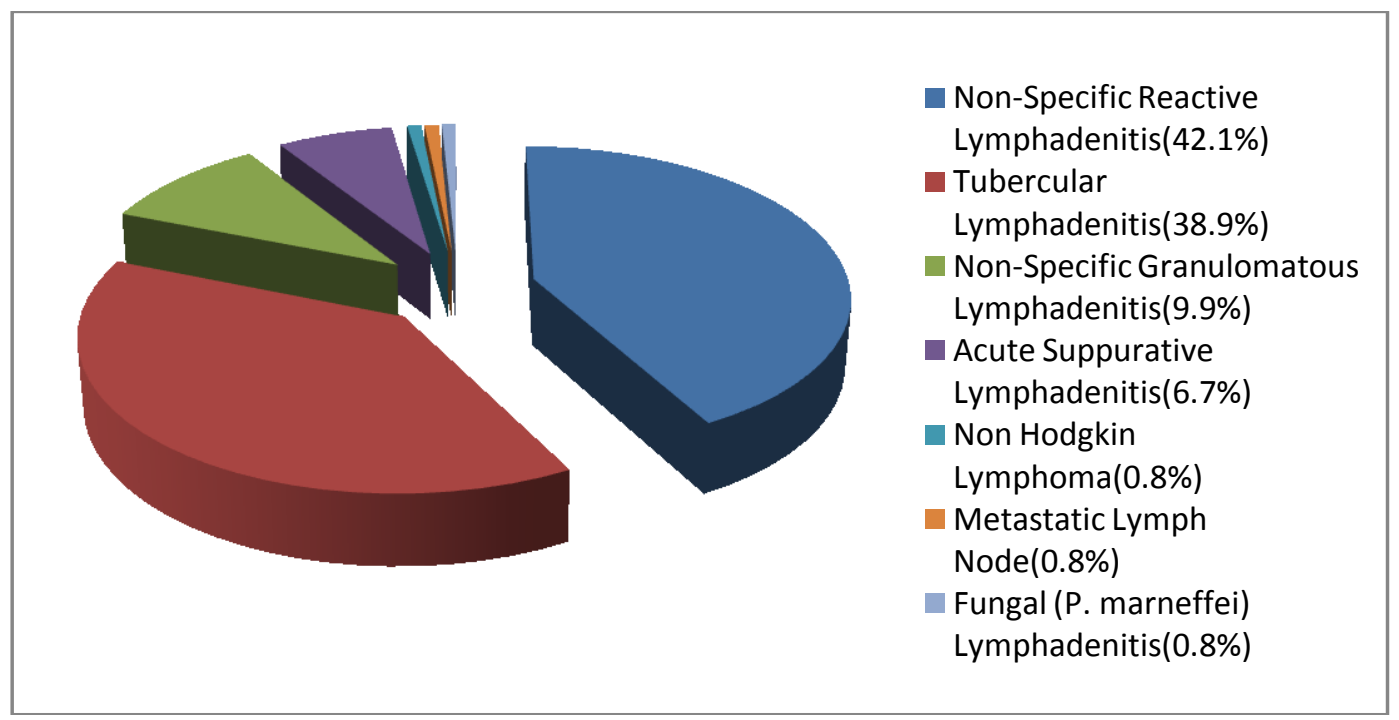

Figure 1.Cytology Diagnosis of Lymphadenopathy in HIV positive patients

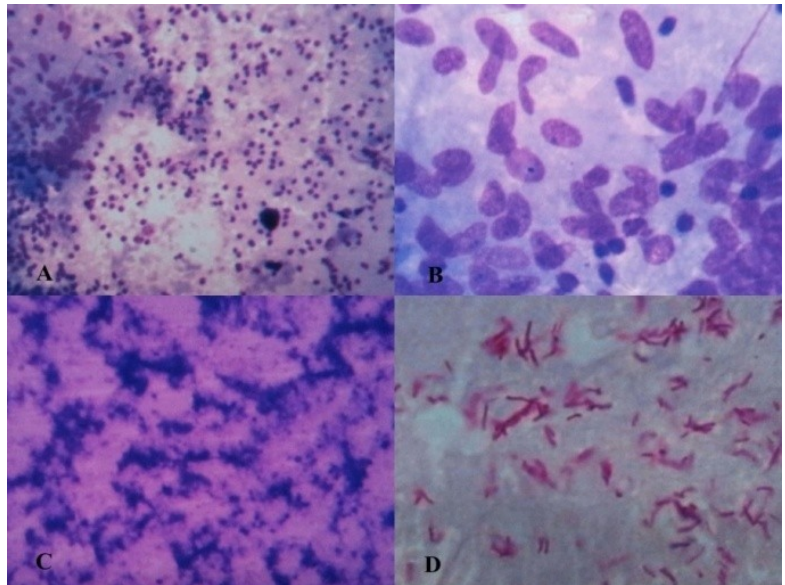

Figure 2. A. Photomicrogragh showing caseation necrosis with granuloma; MGG; x100;

B. High power magnification of A showing the granuloma; MGG; x1000; C. Area with extensive caseation necrosis of the same case; MGG; x100; D. Ziel Nielsen stain showing acid fast bacilli; x1000

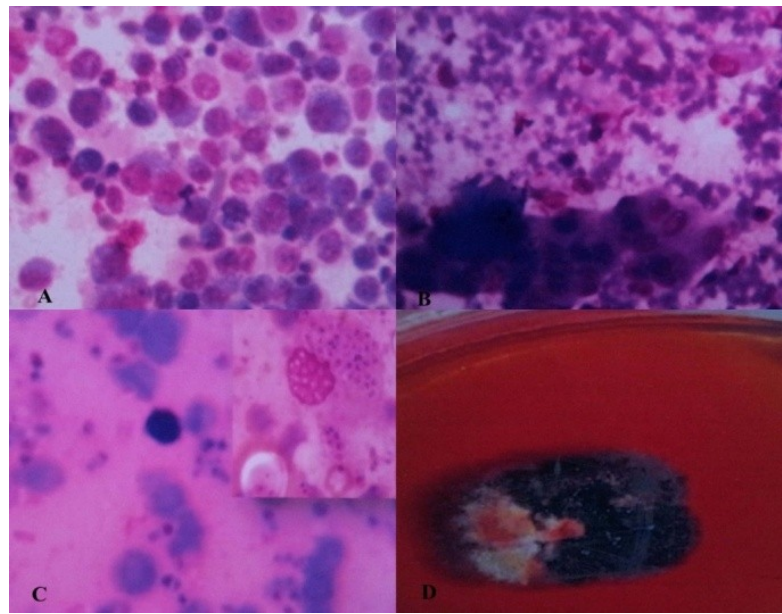

Figure 3. A. Photomigragh showing Non Hodgkin's Lymphoma;MGG; x1000 B. Photomigragh showing malignant epithelial cell in a lymph node aspirate; MGG; $x 400 \mathrm{C}$. Photomicrograph showing Penicillium marneffei; MGG; x400). Inset - Enlarged view showing extracellular and intracellular P marneffei; MGG; x100

D. Culture growth of P. marneffei showing lemon or buff or grayish black colonies with diffuse red pigmentation into the media 


\section{Conclusion}

Based on our study, FNAC is a procedure which is reliable, cost effective with high specificity and less risk to the exposure. It can be used to diagnose the cause of lymphadenopathy in the entire spectrum of HIV infection. CD4 count is considered to be a surrogate marker of the stage of HIV infection.

\section{Acknowledgements}

The authors are grateful and thankful to Prof. D.C. Sharma, Professor, Department of Pathology, Regional Institute of Medical Sciences, India and Prof. Ng. Brajachand, Department of microbiology, Regional Institute of Medical Sciences, India for their encouragement and help. The authors also thankful to Prof. Brogen Singh Akoijam, Professor, Department of Community medicine, Regional Institute of Medical Sciences, India for his immense help in statistical analysis.

the global AIDS epidemic 2012, available from http:/www.unaids.org/en/media/unaids/contentassets/documents/epidemiology/2012/gr2012/20121120 unaids global report 2012 with annexes en, on 10 July 2012

NACO Annual Report 2012-13, available from
http://www.naco.gov.in/upload/Publication/Annual\%20Report/Annual\%20report\%202012-13, on 10 July 2012.

[3]. Pairkh U.R, Goswami H.M, Nanavati M.G, Bisen V.V, Patel S., Menpara C.B, et al.,

[4]. Diagnostic Utility of FNAC in HIV Positive Lymphadenopathy, Journal of Clinical Research Letters, 3(2), 2012,37-40.

[5]. Février M, Dorgham K, Rebollo A, CD4 T Cell Depletion in Human Immunodeficiency Virus (HIV) Infection: Role of Apoptosis, Viruses, 3(5), 2011, 586-612.

[6]. Kumar V, Abbas AK, Fauato N, Aster JC, Diseases of the Immune System, Pathologic basis of disease, 8 (Philadelphia: Saunders Elsevier,2010) 183-258

[7]. Herbeuval J.P, Grivel J.C, Boasso A, Hardy A.W, Chougnet C, Dolan M.J, Hideo et al., CD4 T-cell death induced by infectious and noninfectious HIV-1: role of type 1 interferon-dependent, TRAIL/DR5-mediated apoptosis, BLOOD, 106(10), 2005, 3524- 3531

[8]. Fauci A.S, Lane C, Human Immunodeficiency Virus Disease: AIDS and Related Disorders, in Fauci AS, Kasper DL, Longo DL, Braunwald E, Hauser S.L, Jameson J.L et al (Ed), Harrison's principle of Internal Medicine, 17 ( New York: McGrawHill, 2008) 1137-1204.

[9]. Picerno I, Visalli G, Lentile R, and Piedimonte P, Lymph node involution, T- cell adaptation and T- cell death in HIV infection, HIV Ther, 4(6), 2010, 629-637.

[10]. Bates E.M, Tanner A, Suvarna S.K, Glazer G, and Coleman D.V, Use of fine needle aspiration cytology for investigating lymphadenopathy in HIV positive patients, J Clin Pathol, 46, 1993, 546-566.

[11]. Shobhana A, Guha S.K, Mitra K, Dasgupta A, Neogi D.K, and Hazra S.C, People living with HIV infection / AIDS - A study on lymph node FNAC and CD4 count, Indian J Med Microbiol, 20, 2002, 99-101.

[12]. Nayak S, Mani R, Kavatkar A.N, Puranick S.C, and Holla V.V, Fine needle aspiration cytology in lymphadenopathy of HIV positive patients, Diagn Cytopathol, 29(3), 2003, $146-148$.

[13]. Pandit A.A, Candes F.P, and Khubchandani S.R, Fine needle aspiration cytology of lymph nodes, J Postgrad Med, 33, 1987, 134136.

[14]. Saikia U.N, Dey P, Jindal B, and Saikia B, Fine needle aspiration cytology in lymphadenopathy HIV positive case, Acta Cytol, 45(4), 2001, $589-592$

[15]. Jayaram G and Chew M.T, Fine needle aspiration cytology of lymphnodes in HIV - infected individuals, Acta Cytol, 44(6), 2000, $960-966$.

[16]. Reid A.J, Miller R.F, and Kocjan G.I, Diagnostic Utility of Fine Needle Aspiration Cytology in HIV infected patient with lymphadenopathy, Cytopathology, 9(4), 1998, 230-239.

[17]. Bottles K, Mc Phaul L.W, and Volberding P, Fine Needle Aspiration biopsy of patients with acquired immunodeficiency syndrome (AIDS): experience in an outpatient clinic, Ann Intern Med, 180(1), 1988, 42-45.

[18]. Dominquez A, Pena J.M, and Gonzalez J.J, Spectrum of lymphadenopathy in HIV-positive patients, Prospective analysis of 45 cases, Rev Clin Esp, 184(2), 1989, 57-60.

[19]. Deshmukh A.T, Jagtap M.W, and Nafees N. Cytological Evaluation of Lymphadenopathy in HIV Patients, International Journal of Recent Trends in Science And Technology, 6(3), 2013, 125-129.

[20]. Vanisri H.R, Nandini N.M, and Sunila R, Fine-needle aspiration cytology in human immunodeficiency virus lymphadenopathy, Indian J of pathol microbial, 51(4), 2008, 481-484.

[21]. Kumarguru B.N, Kulkarni M.H, and Kamaker N.S, FNAC of peripheral lymphnodes in HIV-positive patients, Scientific medicine, $1(2), 2009,4-12$

[22]. Bulakh P.M, Deshmukh S.D, Basavraj A, Gogate B.P, Yadav S, Pandit D, et al., Corretation of CD 4 and tubercular lymphadepathy in HIV/AIDS patients, Int Conf AIDS, 14, 2002, 7-12.

[23]. Larsson M, Nguyen L.H.T, Wertheim H.F.L, Dao T.T, Taylor W, Horby P, et al., Clinical characteristics and outcome of Penicillium marneffei infection among HIV-infected patients in northern Vietnam, AIDS Research and Therapy, 9, 2012, 24. 